through the suture line is sufficient. Primary suture is advisable in amputation; but the surgeon must carefully observe the limb for the first three days and be prepared to open the flaps should infection develop.

It is a wise precaution to put all limbs at rest on a splint and to bandage them so that it is unnecessary to remove the bandage that binds the splint to the limb in order to expose the incision.

After-Care of Stumps.-In circular amputations or any amputation in which, for one reason or other, the flaps are retracted and tense, a device, such as the one illustrated in Figure 15, is extremely useful to release tension on the flaps and prevent retraction.

Once the scar is firmly healed, firm bandaging helps to hasten consolidation of the soft parts. It takes from weeks to months for the tissues in a stump to retract completely and consolidate. As soon as the tenderness leaves the stump, movement in all directions of the joint above should be started, and periodic pressure should be made on the stump. A lacing bucket should be worn and the patient urged to move about. At least four or five months should elapse before a permanent limb is secured. Contracture deformity at the knee, hip and elbow joint must always be guarded against, and patients should be frequently examined for such deformity, even though they are up and about and fairly active on a peg.

While amputations, on the whole, are elementary in principle, it is just these elementary principles that are so often overlooked. It is extraordinary to observe how little disability there is from the loss of one limb, provided a useful artificial limb can be worn. It is also surprising how completely disabled a patient is by a painful stump or by an ill fitting limb. A little more care on the part of the surgeon who amputated the limb, or who had the postoperative care of the limb, would avoid most of the bad results observed.

\section{THE NORMAL HEMOGLOBIN STANDARD *}

RUSSELI L. HADEN, M.A., M.D. Associate Professor in Medicine, University of Kansas School of Medicine

KANSAS CITY, KAN.

The clinical estimation of hemoglobin has always been a most unsatisfactory procedure. Few scientific data are available concerning the behavior of hemoglobin in health and in disease. Few of the clinical determinations are of any real value, since nearly all are expressed in relative terms and have no exact meaning.

There are numerous technical difficulties in the way of accurate hemoglobin work. Perhaps the greatest two obstacles, however, have been the lack of a simple method of calibration for hemoglobinometers, and the absence of a uniform standard. All hemoglobinometers are graduated to read in percentages, yet there is no agreement as to what the 100 per cent. shall be equivalent. One reads in a clinical report that the hemoglobin was a certain per cent., but has no exact idea of what the hemoglobin is in terms of grams.

It is usually stated that 100 per cent. on a hemoglobinometer should represent the average normal num-

* From the Department of Medicine, University of Kansas School of Medicine.

Owing to lack of space, this article is abbreviated in ThP Journal by the omission of four tables. The complete article appears in the author's reprints. ber of grams of hemoglobin per hundred cubic centimeters of blood. The hemoglobin content, however, varies with age and sex and with the red cell count. In calculating the color index, we consider 5 million cells per cubic millimeter as 100 per cent. cells. The most logical hemoglobin standard is certainly one which takes as 100 per cent. the average value of hemoglobin in grams per hundred cubic centimeters for each 5 million red cells.

If we accept such a standard as the most desirable one, what is the correct value for this standard and how is it to be determined? Unfortunately, it is impossible to isolate hemoglobin in pure form from blood quantitatively. There are only two available methods by which quantitative determinations may be made. One is the direct oxygen capacity method of Haldane, the other an indirect method employing the spectrophotometer.

Leichenstern, ${ }^{1}$ in 1878 , made sixty-one determinations of hemoglobin on normal individuals of different ages, using the spectrophotometric method. He found that men have $14.14 \mathrm{gm}$. per hundred cubic centimeters, and women $13.10 \mathrm{gm}$. In most of the textbooks of clinical diagnosis, Leichenstern's figures are yuoted, and the statement is made that the normal hemoglobin content of blood is from 13 to $14 \mathrm{gm}$. per hundred cubic centimeters. The accuracy of estimations with the spectrophotometer depends on the correctness of the absorption ratio, which varies with different observers. Williamson, ${ }^{2}$ in 1916, using the same method, made more than 900 determinations in both sexes at all ages, and found that men between the ages of 16 and 60 have $16.92 \mathrm{gm}$. of hemoglobin per hundred cubic centimeters, and women $15.55 \mathrm{gm}$. for the same age interval. The findings of these two workers vary by 20 per cent. The spectrophotometric method is also too difficult and the instrument too expensive to allow it to come into general use as a means of calibrating hemoglobinometers.

The oxygen capacity method is based on the fact, first demonstrated by Haldane, that on the addition of potassium ferricyanid to a solution of oxyhemoglobin, the oxygen is quantitatively released. It is known that $1 \mathrm{gm}$. of hemoglobin combines with 1.34 c.c. of oxygen; hence one can very simply calculate the hemoglobin content from the oxygen capacity. This method, as adapted by Van Slyke ${ }^{3}$ to his blood gas apparatus, is rapid, simple and accurate. It affords an excellent method by which hemoglobin estimations may be made and instruments standardized.

Accepting the oxygen capacity method as the one of choice, it is necessary that we know the normal values for hemoglobin per hundred cubic centimeters for each 5 million cells if we are to express results in terms of percentage. Haldane and Smith, ${ }^{4}$ working with Haldane's original large blood gas apparatus, found the oxygen capacity of twelve normal persons to be 18.5 c.c., corresponding to $13.8 \mathrm{gm}$. of hemoglobin per hundred cubic centimeters. He did not count the erythrocytes in any case. Van Slyke, ${ }^{3}$ Palmer, ${ }^{5}$ Cohen and Smith, ${ }^{6}$ and Newcomer ${ }^{7}$ accept the Haldane

1. Leichenstern, quoted by Sahli: Diagnostic Methods, Philadelphia, W. B. Saunders Company 1911, p. 742 .

2. Williamson, C. S.: The Influence of Age and Sex on Hemoglobin, Arch. Int. Med. 18: 505 (Oct.) 1916.

3. Van Slyke, D. D.: J. Biol. Chem. 33: 31 (Jan.) 1918.

4. Haldane and Smith: J. Physiol. 25, 1899-1900.

5. Haldane and Smith: J. Physiol. 25,189018

6. Cohen, B., and Smith, A. H. : J. Biol. Chem. 39: 489 (Oct.) 1919.

7. Newcomer, H. S.: J. Biol. Chem. 37: 465 (March) 1919. 
standard of 18.5 oxygen capacity as equivalent to 100 per cent., and record the hemoglobin percentage in terms of this scale, although the standard is based on only twelve determinations. The hemoglobin content of a normal blood containing 5 million cells per cubic millimeter, when determined with the Van Slyke apparatus, is equal to about 112 per cent. on the Haldane scale. This scale is evidently not the ideal one to use, since the 100 per cent. is not equal to the hemoglobin content of a normal blood containing 5 million cells per cubic millimeter. Likewise, the reading. would be too high if Leichenstern's figures were used, and too low if Williamson's were employed. Newcomer ${ }^{7}$ has shown, however, that the hemoglobin content of a blood when determined by the oxygen capacity method with the Van Slyke apparatus checks closely with the results that are obtained with the spectrophotometer, provided the correct absorption ratio is used.

To determine the normal average hemoglobin content of blood per hundred cubic centimeters for each 5 million cells, I have counted the erythrocytes and estimated with the Van Slyke apparatus the hemoglobin of fifty-two normal persons. All technical errors in the work have as far as possible been eliminated. The glassware used, including the Van Slyke apparatus, was recalibrated. The hemocytometer and the blood counting pipets were checked by the Bureau of Standards and certified as correct.

The following procedure has been used: Ten cubic centimeters of blood was withdrawn by venipuncture and run into a 200 c.c. Erlenmeyer flask containing $40 \mathrm{mg}$. of dry potassium oxalate. Dilutions of the oxalated blood, 1:200, were made in two red cell counting pipets, and two separate counts made from each pipet. The four counts were averaged for the final result. The Erlenmeyer flask was then so rotated for five minutes as to keep the blood in a thin layer on the sides of the flask. Two determinations of the oxygen capacity were then made in the Van Slyke apparatus. Part of the determinations were made by the method as originally described, ${ }^{3}$ and part by the more recent procedure. ${ }^{\beta}$ Identical results were obtained by the two methods. All calculations have been made as suggested in Van Slyke's recent article, ${ }^{\mathrm{s}}$ making the proper allowance for the nitrogen in physical solution in the blood.

A volume index has been determined on each blood at the same time to show that the cells were of normal size.

The men and women used as normals are physicians, medical students, nurses and hospital employees. Reasonable assurance was made that they are healthy.

The results obtained in normal men between the ages of 18 and 30 are given in Table 1 . The average red cell count is 5.08 millions per cubic millimeters. The oxygen capacity is 21.20 c.c., corresponding to $15.83 \mathrm{gm}$. of hemoglobin per hundred cubic centimeter. These figures are equivalent to an oxygen capacity of 20.85 c.c.; or $15.57 \mathrm{gm}$. of hemoglobin per hundred cubic centimeters for each 5 million cells.

The average of twenty determinations on men between the ages of 30 and 50 (Table 2) shows 4.865 million cells per cubic millimeter and 20.25 oxygen capacity, corresponding to $15.23 \mathrm{gm}$. of hemoglobin per hundred cubic centimeters. When calculated on

8. Van Slyke, D. D., and Stadie, W. C.: J. Biol Chem. $49: 1$ (Nov.) the normal standard basis, we obtain 21.00 c.c. oxygen capacity and $15.65 \mathrm{gm}$. of hemoglobin.

Twelve determinations were made on women between the ages of 20 and 40 . The average count of the red blood cells is 4.26 million per cubic millimeter; the oxygen capacity is 17.33 c.c., and the hemoglobin is $13.34 \mathrm{gm}$. per hundred cubic centimeters. These figures are equivalent to 21.00 c.c. oxygen capacity and 15.65 $\mathrm{gm}$. of hemoglobin per hundred cubic centimeters for each 5 million cells. The details are shown in Table 3.

The results in the fifty-two determinations are summarized in Table 4. The close correspondence of the hemoglobin in both sexes at the ages covered when calculated on the normal standard basis (per hundred cubic centimeters for each 5 million cells) is most striking. We believe that the variation in hemoglobin with age and sex as given by various observers in the past is probably entirely a matter of difference in red cell count. The amount of hemoglobin per cell varies little.

The average normal value found in the fifty-two persons, that is, 20.9 c.c. oxygen capacity, or $15.6 \mathrm{gm}$. of hemoglobin per hundred cubic centimeters for each 5 million cells, represents the ideal and correct figure to accept as corresponding to 100 per cent. on all hemoglobinometers. When the hemoglobin is expressed in percentage in terms of this scale, the color index will always be close to 1.00 .

We suggest that $15.6 \mathrm{gm}$. per hundred cubic centimeters be adopted as a uniform standard for hemoglobinometers, and that readings on this standard be termed the normal scale.

\section{SUMMARY}

All hemoglobinometers should be calibrated in terms of a uniform standard.

The ferricyanid method as adapted by Van Slyke affords the most desirable means of standardization.

The ideal standard takes as 100 per cent. the average normal number of grams of hemoglobin per hundred cubic centimeters for each 5 million red cells.

The average hemoglobin content of the blood of fifty-two normal persons with the Van Slyke apparatus has been determined to be $15.6 \mathrm{gm}$. per hundred cubic centimeters for each 5 million cells.

All hemoglobinometers should be calibrated with the Van Slyke apparatus on this basis, so that 100 per cent. equals $15.6 \mathrm{gm}$. per hundred cubic centimeters.

It is suggested that readings with this standard be called the normal scale.

Origin of Fecal Diagnosis of Hookworm.-Until 1877 the hookworm had been found only at necropsy. A simple method for diagnosing hookworm infection in living beings was still wanting. This was supplied as a direct result of extensive research in Italy. In a paper written in 1878 , Grassi and two brothers, Ernesto and Corrado Parona, demonstrated that hookworm disease could be recognized from ova passed in the feces. Hookworm was still a comparatively unknown malady in 1880 , when the Saint Gothard tunnel was under construction. From the Saint Gothard tunnel, which was completed in 1882, hookworm disease spread over Europe. The tunnelers sought work in European mines, and seemed to revive an epidemic of the malady that had existed in these mines at intervals for centuries. The disease became most severe in the sulphur mines of Sicily; in the gold and sitver mines of Hungary; in the coal mines of Germany, Holland, Belgium and France; in the lead mines of Spain, and in the tin mines of England.-Bibliography of Hookworm Disease, International Health Board, 1922. 